\title{
L'écriture romanesque et l'univers du Mal, textes réunis et présentés par Michel Estève
}

\section{Emanuele Kanceff}

\section{(2) OpenEdition}

1 Journals

\section{Edizione digitale}

URL: https://journals.openedition.org/studifrancesi/38247

DOI: 10.4000/studifrancesi.38247

ISSN: 2421-5856

\section{Editore}

Rosenberg \& Sellier

\section{Edizione cartacea}

Data di pubblicazione: 15 décembre 2004

Paginazione: 645

ISSN: 0039-2944

\section{Notizia bibliografica digitale}

Emanuele Kanceff, «L'écriture romanesque et l'univers du Mal, textes réunis et présentés par Michel Estève», Studi Francesi [Online], 144 (XLVIII | III) | 2004, online dal 30 novembre 2015, consultato il 08 mai 2021. URL: http://journals.openedition.org/studifrancesi/38247 ; DOI: https://doi.org/10.4000/ studifrancesi.38247

Questo documento è stato generato automaticamente il 8 mai 2021.

\section{(c)}

Studi Francesi è distribuita con Licenza Creative Commons Attribuzione - Non commerciale - Non opere derivate 4.0 Internazionale. 


\title{
L'écriture romanesque et l'univers du Mal, textes réunis et présentés par Michel Estève
}

\author{
Emanuele Kanceff
}

\section{NOTIZIA}

AA. VV., L'écriture romanesque et l'univers du Mal, textes réunis et présentés par Michel ESTÈVE, «Études bernanosiennes», 23, «Monsieur Ouine», 3, Paris-Caen, Lettres modernes Minard, 2004, pp. 283 («La Revue des Lettres Modernes», collection fondée et dirigée par Michel MINARD. Éditeur de la Série Georges Bernanos: Michel Estève).

1 Il sessantesimo anniversario della prima pubblicazione di Monsieur Ouine in Brasile, nel 1943, è stato il motivo che ha suggerito questo volume, come prolungamento di numerosi studi anteriori, particolarmente dei numeri 5 (1964) e 10 (1989) delle «Études bernanosiennes». Questo numero vuole esaminare i legami fra strutture estetiche e dimensioni spirituali nella celebre opera di Bernanos, considerata da alcuni il suo capolavoro. Crediamo utile per il lettore offrire intanto precisazioni sul contenuto del volume: Michel ESTÈVE, Avant-propos (pp. 5-6); I. Monsieur Ouine: Robert BENET, «Monsieur Ouine» ou la crise de la parole (p. 9-44); Élie MAAKAROUN, Les Jeux du savoir et du pouvoir (pp. 45-66); Juliette LE BELLEC, Eau et espace métaphorique dans «Monsieur Ouine» (pp. 67-90); Marcelle sтUBв, Jambe-de-Laine ou la folie en ques-tion (pp. 91-118); Pierre GILLE, «Monsieur Ouine» et l'Histoire (pp. 119-146); Juan ASENSIO, Le Démoniaque selon Soren Kierkegaard dans «Monsieur Ouine» (pp. 147-172); Juan ASENSIO, «Au coeur des ténèbres» de Joseph Conrad et Monsieur Ouin» de Georges Bernanos:le regard sur le Mal (pp. 173-228); II. Etudes: Maria Antonietta LA BERBERA, Un Voyage dans des «lieux d'être»: sur les traces de Georges Bernanos et de Jean Sullivan (pp. 231-255); Pierrette RENARD, Georges Bernanos et Mohammed Dib: «Nouvelle histoire de Mouchette» et «L'Infante maure» (pp. 253-268). 
2 I primi tre saggi, complessivamente, vogliono studiare, attraverso la scrittura, i legami che insorgono con i personaggi del romanzo, mentre lo scritto di Marcelle Stubbs si occupa del tema della follia, in relazione ad un personaggio non molto studiato, Jambede-Laine.

3 L'analisi e l'esplorazione del Male non era mai stata così profonda, per Bernanos, prima di Monsieur Ouine. Questo è dovuto, pensa giustamente Pierre Gille, al contesto storico, alla presa di potere dei fascismi in alcune nazioni d'Europa, al crearsi del clima che ha generato la Seconda Guerra mondiale e che egli tenta di ripercorrere, fino a considerare la "parrocchia morta" come il simbolo dell'Europa al momento degli accordi di Monaco.

4 I due studi di Juan Asensio che terminano la parte monografica mettono a confronto la visione del mondo del romanziere francese con quelle di Kierkegaard e di Conrad, applicando al racconto l'idea del Demoniaco sviluppata dal filosofo tedesco - assoluto negativo che non è mai tagliato fuori dal Bene - e cercando nella sua genesi le radici conradiane, analizzando i parallelismi. Per entrambi gli scrittori, del resto, il Male è un pozzo profondo e una frontiera che sta di fronte al viaggiatore perduto e gli rivela dimensioni altrimenti inconoscibili. 